Working techniques. These comprise polishing, grinding, drilling, scratching, rubbing, and colouring. In reference to this last, pieces of hamatite have been found showing traces of scratching.

Culture: (1) Burial customs. The Upper Cave was evidently a burial cave in which the remains were disturbed by animals. Of the mode of burial nothing is known beyond the fact that a quantity of hamatite powder was scattered around tho dead.

(2) Communications. Uppor Palæolithic man of Choukoutien had rolations over a wide area extending 150 kilometres to the north, 350 kilometres to the south and 200 kilometres to the south-east. The indications are marine shells from a sea-coast, of which the nearest point is now $200 \mathrm{~km}$. to the southeast; hrematite, largo-grained and oolitic in struc. ture, iron ore of this nature being known only in the district of Lungkuan, about $150 \mathrm{~km}$. to the north, with high mountain ranges intervening; the big lincoid shell found at the present day only on the south bank of the Yellow River, $350 \mathrm{~km}$. or more to the south.

(3) Clothing. The suggestion of the bono needle is the sewing of cloth, whilo perforated objects point to the passing of string for a necklace ornament. The inference is that some type of clothing with ornaments was in use.
(4) Other elements. Though of the daily life nothing is known, pieces of charcoal and layers of ashes full of free carbon imply the use of fire, while fish vertebra point to the practice of fishing, though no harpoon or hook has been found. The presence of teeth of deer, fox, badger, and pendants of the bones of a big bird suggest that these animals may have been hunted.

Comparison with Europe. As there is no material in China for comparison, no chronological succession can be established. Geologically, the culture is contemporary with the Grand Loess of North China, that is, late Pleistoceno, and as such comparable with the Upper Palæolithic of Europe. The technique of scratching instead of drilling in porforation is more primitive than either Magdalenian or Aurignacian; but at the same time, the techniquo of fashioning beads, the grinding, drilling, polishing, show that the culture could scarcely be more primitive than Mag. dalenian. Hence, though geologically contemporary with either of these cultures, the cultural relation remains an open question.

\footnotetext{
"Weidenrelch, Franz, "On the Earliest Representatives of Modern Mankind recovered on the Soil of East Asia", Peking Natural History Bull., 18, 3 (1939).

"Pel. W. C., "On the Upper Cave Industry." Peking Notural B istory
} Buli., 13, 3 (1039).

\title{
THE VICTORIA FALLS HYDRO-ELECTRIC SCHEME
}

$\mathrm{T}$ HE Victoria Falls and Transvaal Power Company has recently completed a very successful hydroelectric scheme at the Victoria Falls on the Zambezi River. About thirty years ago a proposal for supplying the Rand with power from the Victoria Falls was projected. The overhead transmission lino was to bo 700 miles long and tho pressure 150,000 volts. Although owing to technical difficulties this project could not be realized at that time, yet the Power Company retained its right to develop the power at the Falls, so that if methods of transmission were improved and developed it might become commercially feasible at a later date. The scheme that has just been completed is the first outcome of that arrangement. It is especially interesting owing to the fact that it is completely automatic.

An article by Mr. H. L. Bazalgette giving a full description of the station is published in the OctoberDecember issue of the English Electric Journal, the contractors being the English Electric Co., London. The generating station is situated in the third gorge, known as the 'Silent Pool', at a hairpin bend in the river about two miles downstream from the Falls. It contains two 1,000 kilowatt, automatically controlled units, the purpose of which is to generate power for transmission over a distance of about seven miles to the town of Livingstone, until recently the capital of Northern Rhodesia, and also over a distanco of about two miles to the Falls Hotel which, with the generating station itself, is in Southern Rhodesia.

In 1936 a comprehensive contract was placod with the English Electric Company for the power station and substation equipment. On March 17, 1935, the now power station was opened by the Governor of Northern Rhodesia, who by simply pressing a button started up the first unit under automatic control. In addition to the two purposes mentioned above, the plant will be able to supply any small industries arising around the town of Livingstono, which may eventually becomo the centre of an active industrial area.

The climatic conditions are damp and tropical and were exceptionally trying for the erecting staff, the engine room temperature rising at times to $110^{\circ} \mathrm{F}$. Owing to the fact that the site is a famous beauty spot, great care was taken by tho Power Company in South Africa to obviate disfigurement, and this has been done so successfully that the power station and penstock are practically hiddon by vegetation from passers-by. Boyond a daily visit of inspection, the station runs automatically and is unattended. From the point of viow of health the situation of the station would be unsuitable for the prolonged attendance of an operating staff.

Automatic devices are introduced which give protection from sustained over-current, over-voltage, over-speed, alternator field failure, internal faults, overheated bearings, oil failure and if it takes longer than the normal starting time. Any of these would automatically cause the unit to shut down and the main oil switch to 'trip'.

The erection and placing into service of tho plant was carried out by C. G. T. Clarke, who spent fifteen months on the site. A very interesting and scientific account of tho Victoria Falls, written by him, is quoted in the Journal. It was carried out in cooperation with the Survey Department of the Northern Rhodesia Government. Between the Main Falls and the Devil's Cataract there exists a small valley hitherto unseen by man which presents a splendid spectaclo of beauty with its carpet of maidenhair forn and overhung by evergreen trees. The spray from Devil's Cataract there serves the glado as a natural water-can, and the wator drops 
sparkle in the brilliant sunshine which penetrates the trees. At the bottom of the Devil's Cataract the great pool is always kept in a very turbulent state by the ever-falling torrent, creating waves at least two feet high on the far side of the pool, while the spray rises far above the precipitous sides and produces brilliant rainbows by day or by night at full moon. The wedge-shaped crevice cutting into Cataract Island gives clear evidence of earthquake activity and could not have been caused by erosion of the hard basalt rock. By descending hand over hand by means of a rope attached to a tree on the crest of the Falls on the Eastern Cataract, Mr. Clarke and his assistant got to the bottom of the abyss.

They observed that at the base of the Falls chasm the strata are vertical and run parallel to the Falls, yet the $300 \mathrm{ft}$. of basalt comprising the perpendicular face of the Falls appears to be in five distinct layers in the horizontal plane, each layer boing a shade different in colour. They swam across the pool beyond the base of the Eastern Cataract after convincing themselves that no crocodiles were present. They explored the entire base of the Falls for the first time and state definitely that no traces of animal remains were seen.

With the help of the chief surveyor, Mr. Younger, twelve careful readings of the height of the Falls wero taken. The maximum height was found to bo $355 \mathrm{ft}$., and this spot is at a place on the west side of the "Arm Chair". Devil's Cataract has a drop of $200 \mathrm{ft}$., while the Eastern Cataract is $282 \mathrm{ft}$. high.

\section{ELECTRICALLY MANUFACTURED STEELS}

\begin{abstract}
A
PAPER on elcctrically manufactured steels by

H. 13. Sieveking, of the Central Electricity Board, originally allocated for reading before the Institution of Electrical Engineers on November 23, has been cireulated owing to the decision not to hold meetings for the time being. Ho first gives a description of the two principal types of electric furnaces used; the main products are next discussed from a metallurgical point of view and the advantages and disadvantages of the two types of furnaces for meeting specific requirements are reviewed.
\end{abstract}

For the manufacture of steel two types of furnace have been developed-the arc and the high-frequency induction types. The low-frequency type is rarely used nowadays. Are furnaces aro used for melting or for keeping molten metal hot. Generally they are of the vertical 3-phase 3-electrode type. The furnace comprises a refractory hearth which may be of 'basic' (for example, magnesite, MgO) or 'acid' (for example, silica $\mathrm{SiO}_{2}$ ) material as required and in which the charge is placed. The necessary heat is obtained by electric ares formed between the chargo and the electrodes which project through the roof in triangular formation. In general, an acid lining is cheaper but this typo of lining is 'dead', that is, it does not allow of impurities being removed from the bath. The more expensive basic lining, on the other hand, is suitable for refining. The position of the electrodes is adjusted either by hand or automatically. Hand adjustment is simple but is apt to givo rise to violent fluctuations of power. Some form of automatic control, consisting of an electric motor, or a hydraulic servo motor on each electrode, is to be preferred. A special transformer is used with special tappings which allow of a voltage variation from 60 to 250 during sorvice. The largest size in practice will usually take a charge of about 30 tons. There is one in use in America which has six arcs and will take a charge of 100 tons.

There exist to-day a very large number of alloy steels, some of which present manufacturing difficulties which can only be overcome in an electric furnace. Let us first consider the high-frequency furnace. It has very thin walls but it is possible to get through about fifty charges without relining. 'This corresponds to about one reek's working. 'The advantages of this type of furnace are: the absence of oxidizing at mosphere, no carbon pickup, suitability for intermittent operation and high temperatures are obtainable. The disadvantages are its high capital cost and limited capacity. It is known that an arc furnace load is such that with a good operating power factor the short-circuit current swings to be taken on the mains will not exceed twice full load. The swings usually occur in the first half of the melting period. In Great IBritain until 1934 the proportion of electric steel was nearly constant, with two well-marked exceptions in 1918 and 1926the last year of the War and the year of the General Strike respectively. Since 1934, which corresponds to a period first of trade depression and then of rearmament, there has been a steady increaso in the proportion.

In the United States the electric steol follows very closely the total output of steol. The United States, Germany and Great Britain stand respectively first, second and third in regard to total output, but sixth, eighth and ninth in respect of proportion of electric steel produced, being above only Luxembourg and Belgium. The countries producing the greatest proportion of steel electrically aro Italy and Swedencountries rich in water power and poor in coal, and only standing seventh and eleventh in regard to total output. The world output of electric steel is about 3 per cent of the total, but if Italy and Sweden are omitted the proportion is only 2 per cent. From the tables given in the paper it is evident that in Great Britain the term electric steel must be confined at present to steels which have a high selling price. The weight of finished steel used to-day is far higher than that required in theory as engineers use a high factor of safety: With ordinary steel the material structure is not uniform and therefore the strength of the weakest point must be guessed and the steel dimensioned accordingly. An electric steel, on the other hand, has a very uniform structure and it would therefore seem possible to reduce the factor of safety at least by an amount sufficient to make the total cost of the steel requirements the same whether the steel is manufactured electrically or by one of the other methods. It is undoubtedly along these lines that some countries are working at the present time in order to reduce their internal steel consumption to a minimum. 